ISSN 1112-9867

http://www.jfas.info

\title{
THE EFFICACY OF PSYCHO TRAINING ON IMPROVEMENT OF ORGANIZATIONAL BEHAVIOR AND MENTAL HEALTH
}

\author{
A. M. Shahsavarani ${ }^{1 *}$, E. Zoghifard ${ }^{2}$, M. E. Mishamandani' ${ }^{2}$, M. Mahmoodabadi ${ }^{2}$, A. \\ Mohammadi $^{2}$, \& K. Sattari ${ }^{3}$ \\ ${ }^{1 *}$ Institute of Psycho Bio Socio Economic Sciences, Tehran, Iran \\ ${ }^{2}$ Institute of PsychoBioSocioEconomic Sciences, Tehran, Iran \\ ${ }^{3}$ Institute of Psycho Bio Socio Economic Sciences, Tehran, Iran
}

Published online: 05 June 2016

\begin{abstract}
Introduction: One of the most important issues of organizations in the modern age is to maximize their efficiency via improvement of organizational behavior. Organizational behavior is directly linked to mental health and recent studies have shown the major role of religion in maintaining mental health of people. The aim of the study was to investigate the efficacy of psycho-religious training on improvement of the organizational behavior and mental health.

Method: A group of 120 white collar personnel (60 females and 60 males) chosen by cluster sampling \& divided randomly into two equal experimental and control groups $(n=60 ; 30$ female \& 30 male). The experimental trial was the administration of the psycho-religious training for three weeks, which consisted of twelve 120-minute discussion-group sessions during 12 weeks. In order to assess the mental health, GHQ-28 was administered as pre-test and post-test in both groups.
\end{abstract}

Author Correspondence, e-mail: amirmohammadshi@gmail.com doi: http://dx.doi.org/10.4314/jfas.v8i2s.276

Fundamental and Applied Sciences is licensed under a Creative Commons Attribution-NonCommercial 4.0 International 
Findings: The results of the independent and dependent t-test indicate the positive effect of psycho-religious training on the mental health of the participants in the experimental group in indices of anxiety/insomnia, severe depression, and total health $(\mathrm{p}<.05)$. There were no significant gender differences.

Discussion and conclusion: These findings suggest that incorporation of religious training within the usual modalities of psychological interventions would be beneficial and increase the levels of mental health and organizational behavior. Implications and suggestions are discussed.

Key words: Psycho-religious education, psychoeducation, religion, organizational behavior, mental health, white collar, labor forc.

\section{INTRODUCTION}

Organizations have complex entities. Most of the revolutionary and pioneer sciences, theories, and models have tried to define organizational behavior in its optimum level with adjustment to the present situation of given organizations. Organizational behavior as a domain of science emphasizes on behavior, nature, and actions of individuals/personnel within the organization, while simultaneously studies nature and behavior of organizations within their surrounding environment. It could be suggested that the important aim of organizational behavior studies is to anticipate and explain present and future functioning of personnel and their organization in order to maximize benefits and reduce operational failures (Miner, 2006). Endeavor to adequately cope and deal with issues by optimum emotion management for organizations and their personnel has resulted in complex and wide studies in social interaction, emotional activity, and organizational change. Organizational behavior is a dynamic and expanding domain including various theories and models to describe people and explain individual and group differences of varied personnel in working atmosphere. Traditionally, this domain considered human beings as rational and without emotion. Nowadays, authors put emphasis on emotions as much as rationale and have announced it as an important step to reach organizational efficiency 
(Aktaş, Çiçek, \& Kıyak, 2011; Hartel, Zerbe, \& Ashkanasy, 2005; Roy \& Khastagir, 2016; Styre et al., 2002).

Many factors have direct impact on healthy emotional functioning and organizational behavior of personnel in their workspace. One of such important factors is mental health. The inverse effect of mental health of quality of life of individuals in their private and working life as well as their organizational behavior is widespread and ranges from private-life satisfaction to organizational costs and gross domestic product index (Abrey \& Smallwood, 2014; Eshgh, Aghaeinejad, Peyman, Amirkhani, \& Cheregosha, 2015; G. Lee, 2015; Menati, Niazi, Menati, Khazail, \& Yasini, 2015; Wahrendorf, Blane, Bartley, Dragano, \& Siegrist, 2013). Therefore, mental health is increasingly become a national and global priority and gradually become an important issue of debate and study in various domains of private and working life all around the world. Mental health have attracted attention of many researchers in various domains include, organizational behavior, psychology, sociology, medicine, biostatistics, and economics and nowadays, one of the important component of most major report on occupational and population studies is devoted to mental health (Blanchflower \& Oswald, 2008; Hasheminejad, Moqadam, Mohammadian, \& Amiri, 2013; World Health Organization, 2015).

There are several varied definitions of health and mental health from different frameworks. World Health organization (WHO) has defined health ideally as having a state of full biological, psychological, and social well-being and not only the state of having no disease/illness (World Health Organization, 2001, 2015) which aims on elevation of potential and de facto functioning of human in a tridimensional biopsychosocial model. The main target of mental health, therefore is prevention of mental and psychosomatic problems as well as maintaining the current state of mental health among people in order to establish hygiene and optimum individual and social environment. Moreover, identification of at risk population, treatment of mental disorders and prevention of relapse of such disorders are among other major targets of mental health (Shahsavrani, Shahrani, Sattari, Mohammadi, \& Hakimi Kalkhoran, 2014; World Health Organization, 2001, 2015). Mental health has important impact on quality of work in 
organizational behavior and personnel's occupational efficacy is directly related to their mental health. Hence, in any given organization, maintaining optimum levels of mental health both in intrapersonal level and interpersonal level could be added to the previous goals of mental health. It could be concluded that when personnel have high levels of mental health, their job satisfaction would increase and this would result in the maximum organizational efficiency during the time (TabatabaeiNasab \& Mahmoodi, 2015). Several studies have shown direct impact of negative outcomes of mental health on organizational output and today, with increasing importance of working life in everyday life of adults, there shall be much more focus of mental health and related interventions in order to fortify institutions, organizations and any cooperative beneficial action (Bordbar, Kamani, \& Manouchehri, 2016; Musarezaei, Sararoudi, Fanian, \& Tabatabei, 2014; Pirbalouti, Aghmadi, \& Eshkaftaki, 2013; Rezaei, Hassanzadeh, \& Mirzaian, 2013; Shahsavarani, Marz Abadi, \& Hakimi Kalkhoran, 2015).

There are many factors influencing organizational behavior, emotional health, and mental health of personnel within workplace from which religious and spiritual beliefs have gained increasing importance in recent studies. In fact, even tridimensional biopsychosocial model of human studies is going to become a quadra model of biopsychosociospiritual components (Moradi, Ghalamkarian, \& Heyrat, 2013; Ventis, 1995). In spite of transition to industrial society in the modern era, religious and spiritual values still play a powerful role in regulation of relations with self and surrounding environment. It has been revealed that strong religious orientations result in higher levels of mental health in various sectors of the society, so that religious and spiritual beliefs could be suggested as important influential factors on attitudes, behaviors, and actions of people in their private, working, and social life (Enayat \& Aqapour, 2011; Hemmati \& Aliabad, 2014). In fact, leadership of organization without consideration of religious and spiritual factors, could hardly improve organizational efficiency and communicate with emotional and inner management of personnel. Studies have shown that religion with its beliefs and value systems would result in a multi-level influence on personnel and facilitate their internal commitment to their organization (Arizi, Nouri, Zare, \& Amiri, 2014; Kriger \& Seng, 2005). 
In recent years, studies have shown that religious and spiritual values are still one of the major human demands, because believe in God and having faith empowers human in the process of coping with stress and disasters as well as reducing anxiety, depression, and worry about current and future problems. Studies have suggested that religious and spiritual tendencies have direct association with psychological and physical health (Janbozorgi, 2007). Recent reviews of literature, have found the important role of Islamic religious and spiritual beliefs on reduction of mental problems/disorders and enhancement of mental health among Muslim societies. Anxiety, distress, indecisiveness, substance abuse, depression, violent behaviors, and spouse abuse found to have negative association with religious beliefs. In addition, job performance, mental health, job satisfaction, and cooperative functioning in organizations and social life have positive and direct association with levels of religiosity (Z. Ghahremani, Heidari, Shabani, Aqvami, \& Hariri, 2014; Kadkhodaei \& Hajianfar, 2013; Kazemi \& Bahrami, 2014; Shafiei, 2014).

According to the current points of view, Religion has positive effects of mental health and organizational behavior of personnel (Harick, Fattahi, \& Taghizadeh, 2014; Hashemi, 2015). In short, authors suggest that people with religious and spiritual attitudes in time of confrontation with stressful events interpret in a one or more ways as follow (Bergin, 1991; Hamid, 2009):

1. Evaluate the event as less stressful;

2. After occurrence of stressful event, assume it as an opportunity to their spiritual and religious growth;

3. Interpret the stressful event as God's providence, will, program, and destiny which leaves no choice to escape.

Religious and spiritual systems in their essence have belief systems to justify and explain human psychological mechanisms and its mutual relations with surrounding environments as well as rules for human development and prevention of her/his moral downfall (Kazemi \& Bahrami, 2014). Islamic belief system puts emphasis on improvement of ethics so that its prophet Muhammad (PBUH) defined his most important duty to finalize the virtues and ethics which in its essence have the meaning of enhancement of human tolerance in problematic and stressful 
events (Kadkhodaei \& Hajianfar, 2013). It appears that religious and spiritual beliefs guide people to perfection and hence higher levels of mental health and commitment to organizational goals. Religion in the form of religious commitment in personnel is considered as an essential part of solution of managerial problems of organizations in fast changing new era. Throughout this process, personnel intrinsically, with rational acknowledgement and sufficient awareness, engage themselves to organizational goals and values, as they do in their religious faith. Such engagement ensures higher levels of mental health as well as organizational efficiency which shall be considered more than before (Hashemi, 2015; Kezdy, Martos, Boland, \& Horvath-Szabo, 2011; Milliman, Czaplewski, \& Ferguson, 2003; Ysseldyk, Matheson, \& Anisman, 2011).

Another important factor in religious attitude is its key role on self-perception, which means ones perception about her/his capabilities, skills, characteristics and abilities. Self-perception have been found to have a major impact on mental health and with negative images of self, anxiety, depression, shyness, hopelessness, and even suicidal ideations would occur (Orth, Robins, Trzesniewski, Maes, \& Schmitt, 2009; Toupxane, Gize-Roud, \& Haratiyan, 2014). Religious systems, with creating and providing values beyond human entity, with her/his relation to the supreme power of eternity maintain and enhance intrapersonal and interpersonal self-perception, so that every believer concludes that with more powerful and pure faith, one can reach to higher levels of capabilities and hence, would be more resistant confronting with stressful and disastrous situations. Such belief system would make personnel more tolerant in the process of day-to-day stressful occupational activities and would result in better organizational behaviors and organizational efficiency (Toupxane et al., 2014).

There have been a few studies and papers about the role of religious and spiritual factors on mental health and organizational behavior in Persian population. In a study on the relation between mental health, religious commitment and job performance among university personnel, pathway analysis revealed that religious commitment is a positive predictor of mental health and job performance and mental health has the mediating role in the relation between religious 
commitment and job performance (Hashemi, 2015). In literature reviews, authors have found direct associations between Islamic attitudes, higher mental health levels, more obedience of ethics, and improved organizational behavior among Persian Muslim communities. In addition, Islamic attitudes have negative associations with job burnout, occupational stress, anxiety, depression, psychosomatic problems and job absence (Kadkhodaei \& Hajianfar, 2013; Kazemi \& Bahrami, 2014). In a Persian handicapped population, authors have found that higher levels of faith and internal religious attitudes are associated with less problems of mental health and higher job performance and self-efficacy at private and working life (Z. Ghahremani et al., 2014). Some Q-sorting analysis about mental health indicators in Iran, revealed that mental health in private and working life of Persian population sectors is strongly related to religious and spiritual components, so that improvement of such factors would result in higher levels of mental health and job performance in Iranian society (Mohammadi, Ashtiani, Fallah, \& Ebadi, 2014). In a retrospective study among medical staff, it has been revealed that organizational culture, especially, when adapted to Islamic values, results in a more flexible work atmosphere and higher mental health of personnel as well as increment in their job satisfaction and performance (Pirbalouti et al., 2013)

There are also limited studies about the effectiveness of psychological interventions on reduction of mental health problems and improvement of organizational behaviors in Persian society. A recent study on pregnant women showed that psychoeducation and behavioral-informative training improved pregnant women's mental health and facilitated their adjustment to workplace during pregnancy. In addition, the intervention reduced anxiety, depressive symptoms, and psychosomatic complaints among participants of experiment group of this quasi-experimental study (Karami, Mardani, Shakerinezhad, \& Saki, 2015). In a study on medical staff of a hospital, stress management and relationship skills training (16 hours; four 4-hour sessions), have significantly reduced stress and anxiety among experimental group, compared with wait-list group (Ashtiani, Pirzadi, Yekta, \& Tavallai, 2014). In a quasi-experimental research on personnel of a petrochemical company, 10 sessions of stress management skills training found to 
be influential on reduction of psychological distress as well as enhancement of mental health, job satisfaction and quality of sleep in experimental groups (Harick et al., 2014). In a study on preschool instructors, a package of 21 two-hour sessions of problem solving and anger management skills was administered. Compression of pre-test with post-test showed that problem-solving behaviors and level of well-being of participants increased, whereas aggressive behaviors, anger, depression, anxiety, psychological helplessness, and stress were decreased among them (Yekta, Zardxane, \& Shaomohammadi, 2014). In a study on primary-school teachers, they have been undergone a package of 10 session psychoeducation about intrapersonal and interpersonal socio-emotional life skills training. Results revealed that improvement of socio-emotional skills would result in improvement of mental health, job performance, occupational efficacy, commitment, and motivation among teachers (KarimZadeh, 2014). A meta-analysis on the efficacy of life skills training on mental health of Persian youth showed that life skills training have important influence on reduction of mental health problems, no matter the gender of the participants (Houman, Ganji, \& OmidiFar, 2013).

In spite of direct associations of mental health and religious and spiritual beliefs on organizational behavior, there are no published paper/report about the effectiveness of incorporation of religious issues in psychoeducation and social/life skills training in Persian population. Taking to account that the incidence trend of mental problems in Iran is increasing and prevalence rate is beyond $40 \%$ in total population (Noorbala, Damari, \& Isfahani, 2014), and the Iranian-Islamic life style emphasizes on incorporation of Islamic teachings with modern findings to facilitate social as well as private and working life, the present study aimed to take advantage from combination of Islamic religious ideations about mental health with social/life skills in order to enhance mental health and organizational behaviors of young adults of Iranian labor force.

\section{METHOD}

\subsection{Design}


The design of the present study was experimental using pre-test and post-test and control group. In experimental studies three aims of science (explanation, prediction, and control of actions/behaviors/events) could be satisfied (HassanzZadeh, 2014). Experimental designs with characteristics of randomization and controlling of varied variables in the process of comparison, have a great role in correction of research bias and expansion of borders of causal awareness (Diaz, Jimenez-Buedo, \& Teira, 2015). The aim of experimental design is maximizing the gathered data according to the current budget or minimizing the required budget to reach the desired amount of information. Augmentation of information would be reached by control and reduction of external variables and elimination of intervening variables and bias (Dean, 2015).

\subsection{Participants}

The population of the study comprised all labor force of private sector in the metropolitan city of Tehran. Participants comprised 60 female (mean age $=28.03)$ and 60 male $(29.43)$ white collar labor force from an organization in Tehran which have been chosen by random cluster sampling. Afterwards, 30 female and 30 male randomly assigned to experimental groups (separated by gender) and the remaining consisted control group of the study. The inclusion criteria were age range (between 22 and 35), having bachelor's degree, have no history or present physical/mental problem/disorder/illness, being Muslim, and willing to partake in the study.

\subsection{Procedure}

After the sampling process and random allocation of participants to experimental and control groups, participants administered Persian version of GHQ-28 as pre-test. A week later, psycho religious training package was administered in the form of 12 two-hour sessions consecutively once a week on experimental groups (classes separated by gender in order to make participants more comfortable to participate in the process of training); while control groups participants received no training. A week after the last session of training, all participants of experimental and control groups administered GHQ-28 again, as post-test.

\subsection{Instruments}

\subsubsection{GHQ-28}


In order to assess the level of mental health and related issues in participants of the study, Persian version of 28-item from of General health Questionnaire (GHQ-28) was applied in pre-test and post-test. GHQ-28 is a famous psychological screening tool which has been used in various populations to identify overall mental health status and detect important domains of problematic intrapsychic contexts. This instrument has been used both for non-clinical and clinical populations and have the ability to detect critical and considerable psychological/psychiatric situations. Another attraction of GHQ-28 are the simplicity of its application and analysis of results (Garrido-Elustondo et al., 2016; Koutra, Simos, Triliva, Lionis, \& Vgontzas, 2016; Leiva-Saldaña, Sánchez-Ramos, León-Jariego, \& Palacios-Gómez, 2016; Lestage \& Xu, 2016; Sterling \& Pedler, 2009).

This Questionnaire consists of 4 subscales of somatic symptoms, anxiety/insomnia, social dysfunction, and severe depression respectively. There are 7 items in each subscale. All of the items are scored in a 4-degree Likert scale from 0 (no symptom) to 3 (exact presence of symptom). In addition to scoring each subscale separately, there is total score which indicates general mental health of respondent (total health score). In Persian version of GHQ-28, the cut-off point of nonclinical/suspicious individuals are 6 for each subscale and 23 for general mental health score (Boshlideh, Zakiei, Sahraei, Gilan, \& Askarabadi, 2015; Chesli, Shaeiri, \& Yaghoubi, 2004; Karami et al., 2015). The reliability analyses of Persian version of GHQ-28 are presented in table 1 .

Table 1. Reliability of Persian version of GHQ-28

\begin{tabular}{lclcc}
\hline Study & n & Subscale & \multicolumn{2}{c}{$\begin{array}{c}\text { Cronbach's } \\
\text { Alpha }\end{array}$} \\
\hline (Boshlideh et al., 2015) & & & .92 & - \\
& 591 & Somatization & .88 & \\
& & anxiety/ & .91 \\
& insomnia & .83
\end{tabular}


dysfunction

.91

severe

depression

Total health

score

(Noorbala, Yazdi, Lari, \&

Somatization

Mahdavi, 2011)

Anxiety/

insomnia

social

dysfunction

severe

depression

Total health

score

(Javanmard \& Mamaghani,

773

Somatization $\quad .78$

2013)

anxiety/

.61

insomnia

.60

social

dysfunction

.87

severe

depression

Total health

score

(Mirzaei \& Montazeri, 2013) $\quad$ systematic review (21 $\quad$ Somatization $\quad .71-.97$

$.75-.96$ 


\begin{tabular}{|c|c|c|c|c|}
\hline & studies) & anxiety/ & $.60-.91$ & \\
\hline & & insomnia & $.65-.93$ & \\
\hline & & social & $.78-.95$ & \\
\hline & & dysfunction & $.85-94$ & \\
\hline & & severe & & \\
\hline & & depression & & \\
\hline & & Total health & & \\
\hline & & score & & \\
\hline \multirow[t]{9}{*}{ Present study } & \multirow[t]{9}{*}{120} & Somatization & .81 & \multirow[t]{9}{*}{.83} \\
\hline & & anxiety/ & .75 & \\
\hline & & insomnia & .73 & \\
\hline & & social & .91 & \\
\hline & & dysfunction & .92 & \\
\hline & & severe & & \\
\hline & & depression & & \\
\hline & & Total health & & \\
\hline & & score & & \\
\hline
\end{tabular}

\subsubsection{Psycho-religious training}

The intervention of the present study comprised a combination of psychological and religious training in 12 sessions. Duration of each session was 2 hours and all held consecutively once a week in 12 weeks. The syllabi of the psycho-religious training is presented in table 2. Same-sex instructors were used for each experimental groups.

Table 2. Syllabi and procedure of psycho-religious training

Session Syllabi


1 1. Listening to Holly Quran tartil recitation (5 minutes)

2. Translation of verses in the context of nowadays psychosocial life (10 minutes)

3. The necessity of training and learning the basic teachings of religion (60 minutes)

4. Free discussion (30 minutes)

5. summary and conclusion (15 minutes)

1. Listening to Holly Quran tartil recitation (5 minutes)

2. Translation of verses in the context of nowadays psychosocial life (10 minutes)

3. Findings and results of biopsychosociospiritual scientific studies about efficacy of religious and spiritual trainings on mental, social, and physical health (60 minutes)

4. Free discussion (30 minutes)

5. summary and conclusion (15 minutes)

3 1. Listening to Holly Quran tartil recitation (5 minutes)

2. Translation of verses in the context of nowadays psychosocial life (10 minutes)

3. Instructing principles and bases of Islamic thoughts, Islamic worldview and ideology (60 minutes)

4. Free discussion (30 minutes)

5. summary and conclusion (15 minutes)

4 1. Listening to Holly Quran tartil recitation (5 minutes)

2. Translation of verses in the context of nowadays psychosocial life (10 minutes)

3. The position and status of spirituality and Islam in the modern world (60 minutes)

4. Free discussion (30 minutes)

5. summary and conclusion (15 minutes)

5 1. Listening to Holly Quran tartil recitation (5 minutes) 
2. Translation of verses in the context of nowadays psychosocial life (10 minutes)

3. Adjustment and adaptation of theoretical and practical Islamic rules in everyday life (60 minutes)

4. Free discussion (30 minutes)

5. summary and conclusion (15 minutes)

1. Listening to Holly Quran tartil recitation (5 minutes)

2. Translation of verses in the context of nowadays psychosocial life (10 minutes)

3. Adjustment and modification on biological dimension of life to reach a healthy life style according to Islamic principles (60 minutes)

4. Free discussion (30 minutes)

5. summary and conclusion (15 minutes)

7 1. Listening to Holly Quran tartil recitation (5 minutes)

2. Translation of verses in the context of nowadays psychosocial life (10 minutes)

3. Adjustment and modification on psychological dimension of life to reach a healthy life style according to Islamic principles (60 minutes)

4. Free discussion (30 minutes)

5. summary and conclusion (15 minutes)

1. Listening to Holly Quran tartil recitation (5 minutes)

2. Translation of verses in the context of nowadays psychosocial life (10 minutes)

3. Adjustment and modification on social dimension of life to reach a healthy life style according to Islamic principles (60 minutes)

4. Free discussion (30 minutes)

5. summary and conclusion (15 minutes) 
9 1. Listening to Holly Quran tartil recitation (5 minutes)

2. Translation of verses in the context of nowadays psychosocial life (10 minutes)

3. Adjustment and modification on spiritual dimension of life to reach a healthy life style according to Islamic principles (60 minutes)

4. Free discussion (30 minutes)

5. summary and conclusion (15 minutes)

10 1. Listening to Holly Quran tartil recitation (5 minutes)

2. Translation of verses in the context of nowadays psychosocial life (10 minutes)

3. How to adapt and adjust to new situations using current Islamic principles and rules (60 minutes)

4. Free discussion (30 minutes)

5. 5. summary and conclusion (15 minutes)

11 1. Listening to Holly Quran tartil recitation (5 minutes)

2. Translation of verses in the context of nowadays psychosocial life (10 minutes)

3. Coping and stress management styles in everyday private, working and social life (60 minutes)

4. Free discussion (30 minutes)

5. summary and conclusion (15 minutes)

12 1. Listening to Holly Quran tartil recitation (5 minutes)

2. Translation of verses in the context of nowadays psychosocial life (10 minutes)

3. Applied and practical examples of implementation and modeling from Islamic sources to reduce psychosocial stress and increase mental health (60 minutes).

4. Free discussion (30 minutes)

5. summary and conclusion (15 minutes) 


\subsection{Research ethics}

After finalizing sampling, general process of the study, to the extent which won't make bias, was discussed to all participants. All participants gave written subscription. In order to maintain secrecy and confidentiality, all issues that would somehow consider as private information or could anyhow interfere in the results or make bias, transformed into random codes. After post-test all identity information and contact details of participants were eliminated.

\section{FINDINGS}

Table 3 shows demographic characteristics of the sample group. The comparison of mean differences of age showed no difference between groups in age.

Table 3. Demographic statistics of participants

\begin{tabular}{lcccccccc}
\hline & gender & n & \multicolumn{2}{c}{ age } & t & sig & f & sig \\
& & & mean & sd & & & \\
Experimental group & female & 30 & 32.28 & 3.205 & .821 & .83 & \\
& male & 30 & 32.21 & 3.352 & & & \\
total & 60 & 32.25 & 3.279 & & & & \\
\multirow{2}{*}{ Control group } & female & 30 & 32.51 & 2.809 & .126 & .91 & 3.493 & .74 \\
& male & 30 & 32.89 & 3.492 & & & & \\
total participants & total & 60 & 32.67 & 3.651 & & & & \\
& female & 60 & 32.40 & 3.007 & .319 & .51 & & \\
& male & 60 & 32.55 & 3.442 & & & & \\
& total & 120 & 32.48 & 3.215 & & & & \\
\hline
\end{tabular}

In order to test the hypothesis of the study, psycho-religious training enhance and improve mental health of white collar labor force, analysis of variance (ANOVA) was administered to 
determine the differences between groups. ANOVA showed significant gender differences. Therefore, results of female and male participants were added up to each other both in experimental and control groups. T-test for dependent samples were used to estimate within-group variations before and after experimental intervention in per-test and post-test scores. Moreover, t-test for independent samples were used to compare the inter-group differences before and after psycho-religious training. The results of t-test for dependent samples are presented in table 4 shows significant difference in anxiety/insomnia, severe depression, and total health scores $(\mathrm{p}<.05)$ which means the psycho-religious training were effective in aforementioned domains.

Table 4. T-test for dependent samples

\begin{tabular}{lcccccc}
\hline \multicolumn{1}{l}{ groups } & \multicolumn{2}{c}{ Correlation of pairs } & & & \\
& & correlation & sig & $\mathbf{t}$ & df & sig \\
\hline \multirow{2}{*}{ Experimental } & somatic symptoms & .974 & .005 & -1.613 & 59 & .891 \\
& Anxiety/insomnia & .981 & .005 & -1.021 & 59 & .048 \\
& social dysfunction & .936 & .005 & -1.380 & 59 & .397 \\
& severe depression & .945 & .005 & -1.194 & 59 & .031 \\
& total health score & .979 & .005 & -2.065 & 59 & .025 \\
& somatic symptoms & .841 & .005 & -1.687 & 59 & .067 \\
& Anxiety/insomnia & .245 & .005 & -.543 & 59 & .471 \\
& social dysfunction & .617 & .005 & -1.298 & 59 & .519 \\
& severe depression & .853 & .005 & -.238 & 59 & .951 \\
& total health score & .865 & .005 & -.615 & 59 & .314 \\
\hline
\end{tabular}

T-test for independent groups showed that in pre-test there is no significant differences between experimental and control groups. However, in post-test there are significant differences in anxiety/insomnia $(\mathrm{p}<.001)$, severe depression $(\mathrm{p}<.001)$, and total health score $(\mathrm{p}<.05)$ which 
indicates the significant reduce in scores of aforementioned indices in post-test of experimental group in comparison with control group (table 5).

Table 5. T-test for independent groups

\begin{tabular}{|ccccc|}
\hline & indices & Independent & & \\
& & $\mathbf{t}$ & $\mathbf{d f}$ & sig \\
\hline Pre-test & somatic symptoms & .416 & 58 & .539 \\
& anxiety/insomnia & .672 & 58 & .495 \\
& social dysfunction & -.389 & 58 & .305 \\
& severe depression & .981 & 58 & .168 \\
& total health score & .613 & 58 & .102 \\
& somatic symptoms & .209 & 58 & .492 \\
& Anxiety/insomnia & 2.564 & 58 & .001 \\
& social dysfunction & -.354 & 58 & .238 \\
& severe depression & 2.011 & 58 & .001 \\
& total health score & 2.821 & 58 & .045 \\
\hline
\end{tabular}

\section{DISCUSSION AND CONCLUSION}

The aim of the present study was designing a psycho-religious training package and evaluation of its efficacy in reduction of stress and strain as well as improvement of mental health and organizational behavior among young white collar labor force. In religious societies, the context and unconscious tendency of the society is towards combination of religious thoughts and spiritual factors in every domain of private, working, and social life and hence, there is a great need to incorporate any intervention with religious and spiritual components to maximize the penetration and efficacy of such method (Z. Ghahremani et al., 2014; Hashemi, 2015). According to the statistical findings, it appears that the present study have been succeeded to reach this goal. Anxiety/insomnia, and depressive symptoms have been reduced after 
psycho-religious training intervention phase. In addition, general mental health status improved by using this training method. Up to date, there has been no published study implementing such method to labor force to refer as literature or make comparison. In a study on high school female students, teaching the practical method of life of Prophet Muhammad (PBUH; Siarat al-nabi) resulted in improvement of mental health among participants (Asgari, Sigaroudi, Yousefian, \& Marashian, 2009). In another study on couples, religion-oriented CBT was administered on a group of volunteer couples with family problems. Results indicated that marital adjustment and mental health have been improved significantly in post-test and follow-up and the effect size was greater than administration of CBT (N. Hamidi, Bayegi, \& Dehqani, 2012). In alike study, Islamic CBT was designed and administered on family of veterans and compared to classical model of CBT. The results showed improvements on mental health like classical CBT which suggests the potent evidence of application of religion-based psychological interventions (Mojahed, kalantari, Molavi, Neshatdust, \& Bakhshani, 2010).

There are various studies which have indicated the direct link between spiritual and religious orientation and optimum levels of mental health in Persian population (Almasi \& Moradi, 2012; Arefi \& Mohsenzadeh, 2011; Enayat \& Aqapour, 2011; EtesamiNia, Nosrati, \& Ahmadi, 2015; Hosseini, Mollazadeh, Kazerouni, \& Lari, 2012; Janbozorgi, 2007; Kheydani, 2011; Sadri \& Jafari, 2010). In workplace, however, there are limited descriptive and survey studies which have shown the relation between spiritual/religious factors with mental health of labor force $(\mathrm{N}$. Ghahremani \& Nadi, 2012; Hashemi, 2015; Mofidirad \& Shareh, 2014).

Findings of the present study show a new way of psycho-religious interventions within organization which have positive outcomes in mental health and organizational behavior. Religion has been found to have great potential in helping and supporting its followers in stressful events. Religious systems usually provide their followers with simple and adequate coping strategies in tension and therefore, would be undeniable source of security (Janbozorgi, 2007). Religion has the potential to maintain psychological and mental health of individuals in various life contexts and helps people to reduce the direct confrontation with social, private, and 
occupational stress. Moreover, it can provide individuals with social, spiritual, and psychological resources in order to dealing with real/imaginary perceived stressful events (Ilder, 2015; Koenig, Al Zaben, \& Al Shohaib, 2015). In addition, each religion has a variety of unique coping style which demonstrate such situations as chances of reinforcement of the relation with God and a private and dedicated relation with the source of being (Janbozorgi, 2007; Lownthal, 2015; Shahsavarani et al., 2016).

Religion has the power to engage individuals in (non)official routine rituals which are usually considered as a great context of practicing commitment to a belief system. This in turn guides attitudes of the follower to organize her/his thoughts and actions around reaching the goals of such religion. Therefore, religion, in fact, maintains and regulates commitment behaviors of its followers in everyday life and assists them to reach a calm and peaceful state of mind which results in enhancement of mental health (Bradshaw \& Ellison, 2010; K. H. Lee \& Woo, 2013). Islamic theology have an in-depth principles and rules to regulate intra- and inter-personal attitudes toward psychological/mental health and obedience of order in any aspect of private and social life; there are many solutions for major and minor stressful situations which ensures Muslims they won't get stuck in any confusing situation. Such approach is satisfying and acts as a stress-reducing system of thoughts. Because Islamic teachings are mainly focus on acceleration of joy and pleasure in the framework of Halal pleasure (accepted by religion) and emphasize on making all potential powers to de facto, all Muslim society members can benefit from such context and extend their capabilities, especially in workplace. In short, Islamic ideology tries hard to make ground stones of capacity building and empowerment of all Muslims and hence, increasing mental health and improvement of organizational behavior are some midway milestones through the path to Islamic utopia (Shahsavarani et al., 2016). from a cognitive aspect, psycho-religious Islamic training reduces personal errors of functioning and reinforces the attentional resources of human, which in return reduces distraction from a given task and makes her/him more comfortable and calm while doing her/his duties at workplace (F. Hamidi, Bagherzadeh, \& Gafarzadeh, 2010). 
In conclusion, this study appears to be the first of the kind in design and implement psycho-religious training for young adult white collar labor force to improve mental health and facilitate organizational behavior of a non-clinical population sector of Iranian society. It would be a sound suggestion to replicate such training in wider and various population to identify underlying components of such training. Furthermore, there shall be some comparative studies to determine the effect size of such interventions in comparison to the current and classical modules of psychoeducation.

\section{REFERENCES}

1. Abrey, M., \& Smallwood, J. J. The Effects of Unsatisfactory Working Conditions on Productivity in the Construction Industry. Procedia Engineering, 2014, 85, 3-9. doi:http://dx.doi.org/10.1016/j.proeng.2014.10.522

2. Aktaş, E., Çiçek, I., \& Kıyak, M. The Effect Of Organizational Culture On Organizational Efficiency: The Moderating Role Of Organizational Environment and CEO Values. Procedia - Social and Behavioral Sciences, 2011, 24, 1560-1573. doi:http://dx.doi.org/10.1016/j.sbspro.2011.09.092

3. Almasi, M., \& Moradi, G. Mental health of prisoners of Ilam Province penitentiaries and its related factors. Strategic studies of Social Security and Order, 2012, 1(3), 101-116.

4. Arefi, M., \& Mohsenzadeh, F. Relation between spiritual orientattion, mental health and gender. Woman: Rights and Development (Women Studies), 2011, 5(3), 126-141.

5. Arizi, H. R., Nouri, A., Zare, R., \& Amiri, M. Meta-analysis of studies about the relation between job burnout and mental health. Scientific-Research Journal of Social Welfare, 2014, 13(48), 91-110.

6. Asgari, P., Sigaroudi, E. K., Yousefian, F., \& Marashian, F. The effect of teaching the practical life style of Islam Prophet on relighiou thinking, religious beliefs, and mnetal health of high shcool female students of Ahwaz. Knowledge \& Research in Applied Psychology, 2009, 11(40), 13-25. 
7. Ashtiani, A. F., Pirzadi, H., Yekta, M. S., \& Tavallai, S. A. The Influence of Teaching Program of Stress Management and Communication Skills on Improvement of Mental Health of Nurses and Hospital Staff: An Experimental Study. Iran Journal of Nursing, 2014, 27(90-91), 1-13.

8. Bergin, A. E. Values and Religious Issues in Psychotherapy and Mental health. American Psychologist, 1991, 64(4), 394-403.

9. Blanchflower, D. G., \& Oswald, A. J. Is well-being U-shaped over the life cycle? . Social Sciences \& medicine, 2008, 66, 1733-1749.

10. Bordbar, F. T., Kamani, M. H., \& Manouchehri, B. The relation between believing in mirror-glass and mental success in female personnel of Shiraz municipality. The scientific-research Journal of Woman and Society, 2016, 6(4), 125-143.

11. Boshlideh, K., Zakiei, A., Sahraei, Z., Gilan, N. R., \& Askarabadi, A. M. Simple, multiple and focal relation between alexythymia and percieved stress with mental health. Personality and Individual differences Quarterly, 2015, 4(7), 149-166.

12. Bradshaw, M., \& Ellison, C. G. Financial hardship and psychological distress: Exploring the buffering effects of religion. Social science \& medicine (1982), 2010, 71(1), 196-204.

13. Chesli, R. R., Shaeiri, M. R., \& Yaghoubi, H. The effect of the relation of same consultants on facilitation of mental health and adaptation among new-coming aboriginal university students Daneshvar Raftar, 2004, 12(10), 35-42.

14. Dean, A. M. Experimental design: Overview. In J. D. Wright (Ed.), International Encyclopedia of the Social \& Behavioral Sciences, 2015 (2nd ed., Vol. 8, pp. 535-540). Cambridge, MA, USA: Elsevier.

15. Diaz, A., Jimenez-Buedo, M., \& Teira, D. Quasi- and field experiment. In J. D. Wright (Ed.), International Encyclopedia of the Social \& Behavioral Sciences, 2015, (2nd ed., Vol. 19, pp. 736-741). Cambridge, MA, USA: Elsevier.

16. Enayat, H., \& Aqapour, A. Sociocultrual factors of mental health in families: A case study on Shiraz residents. wWoman and Society Quarterly, 2011, 2, 27-46. 
17. Eshgh, Z. M., Aghaeinejad, A. A., Peyman, A., Amirkhani, A., \& Cheregosha, M. Relationship between occupational stress and mental health in male personnel of medical emergency in Golestan province. Journal of Research Development in Nursing \& Midwifery, 2015, 12(1), 29-38.

18. EtesamiNia, H., Nosrati, R. N., \& Ahmadi, M. R. Relation between religious orientation with mental health and moral development. Psychology and Religion, 2015, 8(1), 115-128.

19. Garrido-Elustondo, S., Reneses, B., Navalón, A., Martín, O., Ramos, I., \& Fuentes, M. Capacidad de detección de patología psiquiátrica por el médico de familia. Atención Primaria(Article in press). 2016, doi:http://dx.doi.org/10.1016/j.aprim.2015.09.009

20. Ghahremani, N., \& Nadi, M. A. Relationship between religious/spiritual components, mental health and hope for the future in hospital staff of Shiraz public hospitals. Iran Journal of Nursing (IJN), 2012, 25(79), 1-11.

21. Ghahremani, Z., Heidari, N., Shabani, M., Aqvami, M., \& Hariri, M. Religious beliefs and mental health among handicapped community members. Scientific-Research Journal of Zanjan University of Medical Sciences, 2014, 22(90), 53-61.

22. Hamid, N. The relation between religious attitude with mental health and functions of autoimmune system. Psychological Studies, 2009, 5(2), 73-88.

23. Hamidi, F., Bagherzadeh, Z., \& Gafarzadeh, S. The role of Islamic education in mental health. Procedia- Social and Behavioral Sciences, 2010, 5, 1991-1996.

24. Hamidi, N., Bayegi, M. E., \& Dehqani, M. Biquarterly Journal of Studies in Islam and Psychology, 2012, 6(10), 85-103.

25. Harick, N. M. D., Fattahi, B. A., \& Taghizadeh, H. The efficacy of stress management learning on mental health, job satisfaction, and qulaity of sleep of eployees of Tabriz Petrochemical Company. Efficiency Management, 2014, 7(27), 145-164.

26. Hartel, C. E. J., Zerbe, W. J. Z., \& Ashkanasy, N. M. Emotions in organizational behavior. New Jersey, NJ, USA: Lawrence Erlbaum Associates, Publishers, 2005. 
27. Hashemi, S. A. The mediating role of mental health on religious commitment with job performance in Islamic Azad University of Lamerd. Pshcychological Methods and Models, 2015, 5(18), 65-79.

28. Hasheminejad, N., Moqadam, S. R., Mohammadian, M., \& Amiri, F. The relation between mental health and occupational stress in midwives of Kerman Hospitals in year 2011. The Journal of Women, Midwifery, and Infertility, 2013, 16(64), 1-9.

29. HassanzZadeh, R. Research methods in behavioral sciences: Applied guide to research. Tehran, Iran: Savalan, 2014.

30. Hemmati, R., \& Aliabad, A. R. The relation between soical supports and mental health: A case study on Khalkhal families. Iran Social Sciences studies, 2014, 11(42), 105-119.

31. Hosseini, S. M. D., Mollazadeh, J., Kazerouni, P. A., \& Lari, M. A. The relationship between attachment styles and religious coping styles with mental health among $\mathrm{HIV}^{+}$patients. Journal of Fundamentals of Mental Health, 2012, 14(1), 6-15.

32. Houman, H. A., Ganji, K., \& OmidiFar, A. The meta-analysis of the effectiveness of life skills training on mental health. Developmental Psychology (Iranian Psychologists), 2013, 10(37), 39-50.

33. Ilder, E. L. Religion and Health: Sociological Considerations. In J. D. Wright (Ed.), International Encyclopedia of the Social \& Behavioral Sciences 2015 , (2nd ed., Vol. 20, pp. 269-272). Cambridge, MA, USA: Elsevier.

34. Janbozorgi, M. Religious orientation and mental health. Research in Medicine, 2007, 31(4), 345-350.

35. Javanmard, G. H., \& Mamaghani, J. Standardization of GHQ-28 Inventory on the Students of Azerbaijan Province of Iran. Procedia - Social and Behavioral Sciences, 2013, 84, 47-52. doi:http://dx.doi.org/10.1016/j.sbspro.2013.06.507

36. Kadkhodaei, Z., \& Hajianfar, J. Ethics role on mental health of the society from the view point of Nahj Al-balagha. Journal of Health System Research, 2013, 9(3), 243-258. 
37. Karami, K., Mardani, A., Shakerinezhad, G., \& Saki, A. Effectivenes of codified educational behavioral program on the mental health of pregnant women. Journal of Shahid Sadoughi University of medical Sciences, 2015, 23(9), 879-889.

38. KarimZadeh, M. Effect of socio-emotional skills training on facilitation of mental health of orimary-school teachers. Scientific-Research Journal of Social Welfare, 2014, 14(53), $131-149$.

39. Kazemi, M., \& Bahrami, B. The role of spiritual belief and Islamic practice in imporvement of mental health and prevention of mental disorders. The Scientific-Research Journal of Zanjan University of Medical Sciences, 2014, 22(90), 62-74.

40. Kezdy, A., Martos, T., Boland, V., \& Horvath-Szabo, K. Religious doubts and mental health in adolescence and young adulthood: the association with religious attitudes. J Adolesc, 2011, 34(1), 39-47. doi:10.1016/j.adolescence.2010.03.003

41. Kheydani, L. The role of religion on mental health of students of universities of Ilam Province, Iran. Quarterly of new Thoughts in Educational Sciences, 2011, 6(3), 63-82.

42. Koenig, H. G., Al Zaben, F. N., \& Al Shohaib, S. Religion and health: Clinical considerations and applications. In J. D. Wright (Ed.), International Encyclopedia of the Social \& Behavioral Sciences 2015 , (2nd ed., Vol. 20, pp. 263-268). Cambride, MA. USA: Elsevier.

44. Koutra, K., Simos, P., Triliva, S., Lionis, C., \& Vgontzas, A. N. Linking family cohesion and flexibility with expressed emotion, family burden and psychological distress in caregivers of patients with psychosis: A path analytic model. Psychiatry Research, 2016, 240, 66-75. doi:http://dx.doi.org/10.1016/j.psychres.2016.04.017

45. Kriger, M., \& Seng, Y. Leadership with inner meaning: A contingency theory of leadership based on the worldviews of five religions. The Leadership Quarterly, 2005, 16(5), 771-806. 
46. Lee, G. Korean Emotional Laborers' Job Stressors and Relievers: Focus on Work Conditions and Emotional Labor Properties. Safety and Health at Work, 2015, 6(4), 338-344. doi:http://dx.doi.org/10.1016/j.shaw.2015.08.003

47. Lee, K. H., \& Woo, H. Stressors, social support, religious practice, and general well-being among Korean adult immigrants. J Evid Based Soc Work, 2013, 10(5), 421-434. doi:10.1080/15433714.2012.759483

48. Leiva-Saldaña, A., Sánchez-Ramos, J. L., León-Jariego, J. C., \& Palacios-Gómez, L. Factores predictores de deterioro cognitivo en población mayor de 64 años institucionalizada y no institucionalizada. Enfermería Clínica, 2016, 26(2), 129-136. doi:http://dx.doi.org/10.1016/j.enfcli.2015.09.006

49. Lestage, P., \& Xu, R. Effets de la pratique de la pleine conscience et du Tai Chi Chuan sur la santé mentale d'étudiants: une étude pilote contrôlée non randomisée. Journal de Thérapie Comportementale et Cognitive, 2016, 26(1), 32-48. doi:http://dx.doi.org/10.1016/j.jtcc.2015.12.003

50. Lownthal, K. M. Psychiatry and religion. In J. D. Wright (Ed.), International Encyclopedia of the Social \& Behavioral Sciences, 2015, (2nd ed., Vol. 19, pp. 307-312). Cambridge, MA, USA: Elsevier.

51. Menati, W., Niazi, M., Menati, R., Khazail, S., \& Yasini, A. The relation between job stress measuered by effort-reward imbalance model and mental health in the nurses working in government hospital of Ilam. Sadra Scientific Journal of Medical Sciences, 2015, 3(4), 247-258.

52. Milliman, J, Czaplewski, A. J., \& Ferguson, J. Workplace spirituality and employee work attitudes: An exploratory empirical assessment. Journal of Organizational Change Management, 2003, 16(4), 426-447. doi:doi:10.1108/09534810310484172

53. Miner, J. B. Organizational Behavior (Vol. 3): Historical origins, theoretical foundations, and the future. London, UK: M. E. Sharpe, 2006. 
54. Mirzaei, M., \& Montazeri, H. Over-use of questionnaires in conducting research in Iran: Two cases. Journal of Medical Education and Development, 2013, 8(2), 77-89.

55. Mofidirad, A., \& Shareh, H. Psychological status of penitentiary workers of Khorasan Razavi Province, Iran. Journal of Fundamentals of Mental Health, 2014, 16(1), 74-84.

56. Mohammadi, K., Ashtiani, A. F., Fallah, P. A., \& Ebadi, A. Development of Mental Health Indicators in Iran. Journal of Health Education and Health Promotion, 2014, 2(1), 37-48.

57. Mojahed, A., kalantari, M., Molavi, H., Neshatdust, H. T., \& Bakhshani, N. Comparison of Islamic oriented and classical cognitive behavioral therapy on mental health of martyrs' and veterans' wives. Journal of Fundamentals of Mental Health, 2010, 11(4), 282-291.

58. Moradi, A., Ghalamkarian, S. M., \& Heyrat, A. A Meta-Analysis about Researches on Relationship between Religious Orientation and Mental Health and Depression in Iran. International Research Journal of Applied and Basic Sciences, 2013, 5(7), 829-838.

59. Musarezaei, A., Sararoudi, R. B., Fanian, N., \& Tabatabei, S. M. Predictors of nurses' mental health in medical and surgical wards based on demographic variables. Research in behavioral Sciences, 2014, 12(3), 369-379.

60. Noorbala, A. A., Damari, B., \& Isfahani, S. R. Evaluation of mental disorders incidence trend in Iran. Daneshvar Medicine (Scientific-Research Journal of Shahed University), 2014, 21(112), 1-11.

61. Noorbala, A. A., Yazdi, S. A. B., Lari, M. A., \& Mahdavi, M. R. V. The mental health Status of individuals uper than 15-years old in the City of Tehran in year 2008. Journal of Psychiatry and Vlinical Psychology (Andishe va Raftar), 2011, 16(4), 479-483.

62. Orth, U., Robins, R. W., Trzesniewski, K. H., Maes, J., \& Schmitt, M. Low self-esteem is a risk factor for depressive symptoms from young adulthood to old age. J Abnorm Psychol, 2009, 118(3), 472-478. doi:10.1037/a0015922

63. Pirbalouti, M. G., Aghmadi, R., \& Eshkaftaki, S. S. A. Association of organizational culture and job stress with mental health in nurses in Hajar and Kashani hospitals of Shahrekord city. Journal of clinical Nursing and Midwifery, 2013, 2(3), 53-63. 
64. Rezaei, Z., Hassanzadeh, R., \& Mirzaian, B. The comparison of marital satisfaction, life style and mental health in retired and non-retired men and women. Knowledge \& Research in Applied Psychology, 2013, 14(4), 54-61.

65. Roy, M., \& Khastagir, D. Exploring role of green management in enhancing organizational efficiency in petro-chemical industry in India. Journal of Cleaner Production, 2016, 121, 109-115. doi:http://dx.doi.org/10.1016/j.jclepro.2016.02.039

66. Sadri, J., \& Jafari, A. Relation between religious beliefs and mental health: A case study on Students of Azad University of Abhar. Quarterly of Behavioral Sciences, 2010, 2(3), $123-138$.

67. Shafiei, A. Spiritual intelligence and its effect on menta health of organizational human resource. Biquarterly Journal of Studies in Islam and Psychology, 2014, 8(14), 153-179.

68. Shahsavarani, A. M., Marz Abadi, E. A., \& Hakimi Kalkhoran, M. Stress: Facts and Theories through literature review. International Journal of Medical Reviews, 2015, 2(2), 230-241.

69. Shahsavarani, A. M., Marz Abadi, E. A., Mohammadi, A. R., Sattari, K., Fartoosi, F., Lotfian, M., \& Hakimi Kalkhoran, M. Theoretical bases of stress in Islamic approach: A systematic review of medical, psychological, behavioral, and social issues from the religious viewpoint. Quran and Medicine(Article in press), 2016.

70. Shahsavrani, A. M., Shahrani, H., Sattari, K., Mohammadi, M., \& Hakimi Kalkhoran, M. Psychometric Characteristics and factor structure of Children and Adolescents depression Scale (CADS) and depression status among female adolescents. Counseling Research, 2014, 12(48), 91-121.

71. Sterling, M., \& Pedler, A. A neuropathic pain component is common in acute whiplash and associated with a more complex clinical presentation. Man Ther, 2009, 14(2), 173-179. doi:10.1016/j.math.2008.01.009

72. Styre, A., Ingelgard, A., Beausang, P., Castenfors, M., Mulee, K., \& Roth, J. Emotion management and stress: Managing ambiguities. Organization Studies, 2002, 23(1), $83-103$. 
73. TabatabaeiNasab, S. E., \& Mahmoodi, A. Investigation of the relationship between mental health and organizational employees' work fatigue and deputyships of Yasouj Medical Science University. Armaghane-Danesh: Yasuj University of Medical Sciences Journal (YUMSJ), 2015, 20(5), 444-452.

74. Toupxane, M. Z., Gize-Roud, S. K. M., \& Haratiyan, A. The relation between hidjab, self-perception nad mental health. Psychology and Religion, 2014, 7(3), 81-92.

75. Ventis, L. W. The relationship between religious beliefs and mental health. Journal of Special Issues, 1995, 51(2), 33-48.

76. Wahrendorf, M., Blane, D., Bartley, M., Dragano, N., \& Siegrist, J. Working conditions in mid-life and mental health in older ages. Advances in Life Course Research, 2013, 18(1), 16-25. doi:http://dx.doi.org/10.1016/j.alcr.2012.10.004

77. World Health Organization. The World Health Organization Report 2001: Mental Health: New Understanding, New Hope. Geneva, Switzerland: WHO Press, 2001.

78. World Health Organization. Mental health atlas 2014. France: WHO Press, 2015.

79. Yekta, M. S., Zardxane, S. A., \& Shaomohammadi, K. Effectiveness of anger management and problem solving edducation on mental health and nurturing styles of preschool educators. Journal of School Psychology, 2014, 2(4), 98-117.

80. Ysseldyk, R., Matheson, K., \& Anisman, H. Coping with identity threat: The role of religious orientation and implications for emotions and action intentions. Psychology of Religion and Spirituality, 2011, 3(2), 132-148.

\section{How to cite this article:}

Shahsavarani A M, Zoghifard E, Mishamandani E M, Mahmoodabadi M, Mohammadi A, Sattari $\mathrm{K}$. The efficacy of psycho training on improvement of organizational behavior and mental health. J. Fundam. Appl. Sci., 2016, 8(3S), 1271-1299. 